\title{
Effectiveness of methylprednisolone therapy in patients with a high-risk common type of COVID-19 pneumonia: a retrospective cohort study
}

\author{
Lei Liu ${ }^{1} \cdot$ Hang $\mathrm{Qu}^{2}$. Jun Jian $\mathrm{Li}^{2} \cdot$ Yan Wei Yang ${ }^{2} \cdot$ Qiu Xi Zeng ${ }^{3} \cdot$ Yan Wen Gong ${ }^{3}$ Z Zhong Zhi He $\mathrm{Hi} \mathrm{He} \mathrm{Zhang}^{3}$. \\ Wei Zhang ${ }^{3} \cdot$ Bin Liu $^{2} \cdot$ Li Chun Che $^{2}$ (I)
}

Received: 25 September 2021 / Accepted: 4 October 2021 / Published online: 22 October 2021

(C) The Author(s), under exclusive licence to Springer Nature Switzerland AG 2021

\begin{abstract}
The optimal timing of glucocorticoid treatment for coronavirus disease 2019 (COVID-19) pneumonia is uncertain. We evaluated the clinical outcomes of methylprednisolone therapy (MPT) for patients with a high-risk common type (HRCT) COVID19 pneumonia. We conducted a multicenter retrospective cohort study in Northeast China. A comparison was performed between the standard treatment (SDT) group and the SDT + MPT group to determine the efficacy of methylprednisolone in treating HRCT COVID-19 pneumonia. We collected the medical records of 403 patients with HRCT COVID-19 pneumonia (127 in the SDT + MPT group and 276 in the SDT group). None of the patients had received mechanical ventilation or died. Furthermore, there were no side effects associated with MPT. Patients in the SDT + MPT group treated with methylprednisolone received an intravenous injection for a median interval of five days (interquartile range of 3 to 7 days). The trends in lymphocyte count, C-reactive protein, interleukin 6, lactic acid dehydrogenase, respiratory rate, $\mathrm{SpO} 2, \mathrm{PaO} 2, \mathrm{D}$-dimer and body temperature were similar between the SDT + MPT and SDT groups. The results for the SDT + MPT group seemed to improve faster than those for the SDT group; however, the results were not statistically significant. Clinical outcomes revealed that the average hospitalized days and the rate of progression to severe type COVID-19 pneumonia in both the SDT + MPT group and the SDT group were $14.56 \pm 0.57$ days versus $16.55 \pm 0.3$ days $(p=0.0009)$ and $21.26 \%(27 / 127)$ versus $32.4 \%$ (89/276) $(p=0.0247)$, respectively. The 16-day nucleic acid negative rate was higher in the SDT + MPT group than in the SDT group, $81.73 \%$ (104/127) versus 65.27\% (180/276) $(p=0.0006)$. MPT effectively prevents patients with HRCT COVID19 pneumonia from progressing to the severe stage.
\end{abstract}

Keywords COVID-19 pneumonia $\cdot$ A high-risk common type $\cdot$ Methylprednisolone therapy $\cdot$ Optimal timing

Lei Liu and Qiu Xi Zeng these authors contributed equally to this work.

$\triangle$ Li Chun Che

118402@hrbmu.edu.cn

1 Department of Respiratory Medicine, The First Affiliated Hospital of Hainan Medical University, Haikou, China

2 Department of Respiratory and Critical Care Medicine, The First Affiliated Hospital of Harbin Medical University, Harbin, China

3 Kang'an Hospital of Mudanjiang, Mudanjiang, China

\section{Introduction}

COVID-19 threatens global health and affects the global economy due to its rapid spread and many confirmed cases that occurred in a short period $[1,2]$. No effective antiviral drugs have been developed thus far, although several drugs are in clinical trials. Clinical research has proven that some clinical manifestations of severe pneumonia, such as high fever, shortness of breath, progressive pneumonitis, severe complications and even risk of death, are all related to inflammatory factors [3]. The use of glucocorticoids in patients with severe COVID-19 is still controversial [4-8]. However, an increasing number of studies have shown that glucocorticoids effectively treat severe COVID-19 pneumonia because of their anti-inflammatory benefits and relief of dyspnea [9-16]. Some results showed that patient survival 
and better clinical outcomes with severe COVID-19 were higher in patients treated with glucocorticoids than in those not treated [10, 15]. Furthermore, one large trial has reported in patients hospitalized with Covid-19, the use of dexamethasone resulted in lower 28-day mortality among those who were receiving either invasive mechanical ventilation or oxygen alone at randomization but not among those receiving no respiratory support [16].

Most patients will have a mild type or common type of COVID-19 pneumonia. However, older persons and those with comorbidities may quickly develop severe COVID-19 pneumonia, necessitating hospitalization and time in the intensive care unit (ICU) [17, 18]. The substantial cost of treatment and higher fatality rate in patients with a severe type of COVID-19 pneumonia is known. Extraordinary efforts are being made to prevent patients with a mild and common type of COVID-19 pneumonia from progressing to the severe type of COVID-19 pneumonia. An early short course of methylprednisolone in patients with a mild or common type to severe type of COVID-19 pneumonia reduced the escalation of care and improved clinical outcomes [12]. However, the optimal timing of methylprednisolone treatment for COVID-19 pneumonia remains unclear.

We postulated that early treatment with a short course of methylprednisolone in patients with COVID-19 pneumonia might reduce excessive host respiratory and systemic inflammatory responses, which effectively result in the prevention of severe disease progression in patients with a common type of COVID-19 pneumonia. Therefore, when patients have a high-risk common type of COVID-19 pneumonia, treatment with methylprednisolone treatment should be considered, and treatment during this period may be optimal. This study reported the clinical characteristics and early outcomes of patients with a high-risk common type of COVID-19 pneumonia receiving short courses of methylprednisolone.

\section{Methods}

\section{Clinical classification}

This study focused on adult patients diagnosed with COVID19 pneumonia, according to the World Health Organization (WHO) interim guidance [19]. The patients with COVID-19 pneumonia were divided into four types [20]:

1. Mild type: a type characterized by fever and mild respiratory symptoms, with pulmonary imaging such as computed tomography (CT) showing no apparent or only mild pneumonia.

2. Common type: there are obvious respiratory symptoms such as fever and cough, and pulmonary CT indicates typical coronavirus pneumonia with overall lesions less than $30 \%$. However, common type patients have stable vital signs and oxygen saturation $>93 \%$ without oxygen support.

3. Severe type: diffuse lesions are noted on chest CT and are rapidly progressing to $>50 \%$ within $48-72 \mathrm{~h}$ (evaluated by two physicians and two radiologists) and satisfying at least one of the following criteria: (a) respiratory rate $\geq 30 / \mathrm{min}$, (b) pulse oximeter oxygen saturation $(\mathrm{SpO} 2) \leq 93 \%$ at rest on room air and (c) the ratio of the partial pressure of arterial oxygen $(\mathrm{PaO} 2)$ to the fraction of inspired oxygen $(\mathrm{FiO} 2) \leq 300 \mathrm{~mm} \mathrm{Hg}(1 \mathrm{~mm}$ $\mathrm{Hg}=0.133 \mathrm{kPa})$.

4. Critical type: type that satisfies at least one of the following criteria: (a) respiratory failure requiring mechanical ventilation, (b) shock and (c) failure of other organ systems requiring care in the ICU.

In addition, we divided the patients with the common type COVID-19 pneumonia into two subtypes: (1) generally common type and (2) high-risk common type. The features of the two subtypes are shown in Fig. 1.

Patient improvement allowing for discharge was achieved when the following criteria were satisfied: (a) body temperature returned to normal for $>3$ days, (b) respiratory symptoms were relieved, (c) nucleic acid tests were negative (two times with an interval $>24 \mathrm{~h}$ ), and (d) pulmonary imaging showed that the acute exudative lesions were significantly improved and limited. The features are shown in Fig. 1.

The features associated with the progression to severe COVID-19 were equivalent to the features of the severe type above.

\section{Patient selection}

This research was a retrospective, multicenter cohort study in which patients with the high-risk common type COVID19 pneumonia were enrolled. Data from the medical records of 403 patients with a high-risk common type COVID-19 pneumonia were collected for analysis. All patients were admitted to the Qun'li branch of the First Affiliated Hospital of Harbin Medical University and Kang'an Hospital of Mudanjiang, Peoples' Republic of China, from January to July 2020. Patients who had previously used hormones or who were immunosuppressed within the past 3 months were excluded from the study.

Ethical approval was granted by the institutional ethics board of the Qun'li branch of the First Affiliated Hospital of Harbin Medical University and Kang'an Hospital of Mudanjiang to analyze clinical data from COVID-19-infected inpatients. Informed written consent was waived by the Ethics Commission of the Qun'li branch of the First Affiliated Hospital of Harbin Medical University and Kang'an Hospital, considering the study's retrospective nature and the 
Clinical classification of patients with COVID-19

(1)Mild type (2)Common type

(3)Severe type (4) Critical type

Research objects: common type

Characteristics 1 Fever 2CT: typical coronavirus pneumonia with overall lesions less than $30 \%$. 3 Respiratory symptoms: cough, dyspnea, sore throat,etc.

\begin{tabular}{|c|c|}
\hline Generally common type & High-risk common type \\
\hline $\begin{array}{l}\text { Characteristics } \\
\text { 1+2+3+4+ } \\
5 \\
\text { (4) Respiratory rate } \\
<24 / \mathrm{min} \\
5 \text { In the resting } \\
\text { state, means oxygen } \\
\text { saturation > } 95 \% \\
\text { with no oxygen }\end{array}$ & $\begin{array}{l}\text { Characteristics } 1 \text { + } 2+3+4 \\
\text { (4) Progression of pneumonia area } \\
>50 \% / 2-3 \text { days } \\
\text { (5)At least three of the following criterias } \\
\text { (i)Age }>65 \text { year } \\
\text { (ii)Comorbidities:hypertension, coronary heart } \\
\text { disease, diabetes, obesity, chronic lung disease. } \\
\text { (iii)lymphocyte count in peripheral blood } \\
\text { progressively }<0.8 \times 10^{9} / \mathrm{L} \\
\text { (iv) CRP }>8 \mathrm{mg} / \mathrm{L} \text { and IL- } 6>7 \mathrm{pg} / \mathrm{mL} \\
\text { (v) Lactic acid in peripheral blood }>2.3 \mathrm{mmol} / \mathrm{L} \\
\text { (vi) Lactate dehydrogenase is more than } 2 \text { times } \\
\text { higher than the upper limit of normal value } \\
\text { (vii)D-dimer }>0.5 \mathrm{mg} / \mathrm{L} \\
\text { (viii) } 30 / \mathrm{min}>\text { Respiratory rate } \geq 24 / \mathrm{min} \\
\text { (ix) In the resting state, } 93 \%<\text { means oxygen } \\
\text { saturation } \leq 95 \% \text { with no oxygen }\end{array}$ \\
\hline
\end{tabular}

\begin{tabular}{|c|c|}
\hline $\begin{array}{l}\text { Characteristics (1)At least one of } \\
\text { the following criterias } \\
\text { (i)respiratory rate } \geqslant 30 / \mathrm{min} \\
\text { (ii)pulse oximeter oxygen } \\
\text { saturation } \leqslant 93 \% \text { at rest on room } \\
\text { air (iii)ratio of partial pressure of } \\
\text { arterial oxygen to fraction of } \\
\text { inspired oxygen } \\
300 \mathrm{mmHg}(1 \mathrm{mmHg}=0.133 \mathrm{kPa}) \text {. } \\
\text { (2) Progression of pneumonia } \\
\text { area }>50 \% / 2-3 \text { days }\end{array}$ & $\begin{array}{l}\text { Characteristics (1)Body } \\
\text { temperature returned to normal } \\
\text { for more than } 3 \text { days } \\
\text { (2) Respiratory symptoms were } \\
\text { relieved (3) The nucleic acid test } \\
\text { result of respiratory tract sample } \\
\text { was negative ( } 2 \text { times, with an } \\
\text { interval of more than } 1 \text { day) } 4 \text { CT: } \\
\text { the acute exudative lesions were } \\
\text { significantly improved and limited }\end{array}$ \\
\hline
\end{tabular}

Fig. 1 Clinical classification and characteristics of patients with a high-risk common type COVID-19 pneumonia

urgency of reporting emerging infectious diseases. The study conforms to the Enhancing the Quality and Transparency of Health Research (EQUATOR) guidelines [21]. Finally, this study complied with the ethical principles for medical research involving human subjects in the Declaration of Helsinki [22].

Epidemiological, clinical, laboratory characteristics, radiological characteristics and treatment and outcome data were obtained using data collection forms from electronic medical records. A trained team of physicians reviewed the data. Medical records included clinical characteristics, laboratory parameters, treatment approaches and clinical outcomes. Recorded information included demographic data, medical history, underlying comorbidities, symptoms, signs, laboratory findings, chest CT scans, treatment measures (i.e., antiviral therapy and methylprednisolone therapy) and treatment outcome.

Clinical characteristics and laboratory parameters included white blood cell count (WBC), lymphocyte count, C-reactive protein (CRP), interleukin 6 (IL-6) level, lactic acid dehydrogenase (LDH), days from onset of symptoms to hospitalization, respiratory rate, oxygen saturation $(\mathrm{SpO} 2)$ and pressure of arterial oxygen $(\mathrm{PaO} 2)$. COVID-19 was confirmed by detecting SARS-CoV-2 RNA in throat swab samples using a virus nucleic acid detection kit according to the manufacturer's protocol (Shanghai BioGerm Medical Biotechnology Co., Ltd) by the centralized clinical microbiology laboratory of Heilongjiang Province according to the WHO interim guidance.

\section{Treatment approaches}

Treatment approaches were adopted for patients with the common type COVID-19 pneumonia. For this type, noncontinuous middle-flow oxygen therapy (3-5 L/min), triple antiviral treatment with oral arbidol tablets $(200 \mathrm{mg}$ three times daily), ribavirin (500 mg every $12 \mathrm{~h}$ intravenously) and recombinant interferon-a (five million units twice daily via aerosol) were given. The detailed treatment plans for standard treatment (SDT) and methylprednisolone therapy (MPT) are shown in Fig. 2. Methylprednisolone therapy was $1-2 \mathrm{mg} / \mathrm{kg} / \mathrm{d}$ in two divided doses for 3-7 days. Patients who received methylprednisolone therapy according to standard clinical practice were assigned to the SDT + MPT group, while patients who did not were assigned to the SDT group. Empirical antibiotic treatment was considered for patients with common type pneumonia if a bacterial infection was suspected. Low molecular weight heparin was also considered for use if the D-dimer level was high.

The decision to prescribe methylprednisolone was at the discretion of the treating physician because methylprednisolone was not included in the local COVID-19 protocol at the time of the study. Details of methylprednisolone use (including the timing of initiation, dosing and type of medications) were recorded. Likewise, the choice of the common type COVID-19 pneumonia treatments other than methylprednisolone was at the treating physician's discretion. In the treatment cohort, the first day of administration was considered the index date (Day 1). 


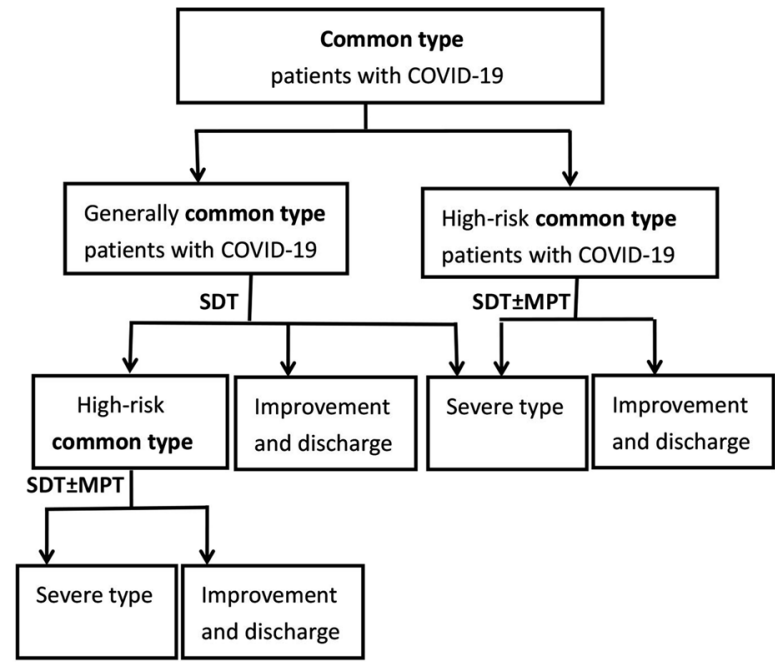

\begin{tabular}{|c|c|}
\hline \multicolumn{2}{|l|}{ Abbreviations } \\
\hline SDT: Standard treatment & Methylprednisolone therapy \\
\hline $\begin{array}{l}\text { Triple antiviral treatment including arbidol, } \\
\text { ribavirin and recombinant interferon- } \alpha \text {. } \\
\text { The recommended duration of antiviral } \\
\text { treatment was } 10 \text { days. } \\
\text { It was not recommended to use three } \\
\text { antiviral drugs at the same time. } \\
\text { Prevention of bacterial infection, relieving } \\
\text { cough, eliminating phlegm, and nutritional } \\
\text { support were commonly used for all of the } \\
\text { patients. }\end{array}$ & $\begin{array}{l}\text { MPT should be given } \\
\text { immediately on } \\
\text { admission or within the } \\
\text { first three to seven days } \\
\text { of hospitalization. } \\
\text { Dose and timing : } 1-2 \\
\mathrm{mg} / \mathrm{kg} / \mathrm{d} \text { in } 2 \text { divided } \\
\text { doses for 3-7days. }\end{array}$ \\
\hline
\end{tabular}

Fig. 2 Clinical classification and prognosis of patients with a highrisk common type COVID-19 pneumonia in the two groups

\section{Statistical analysis}

Quantitative variables are expressed as the mean and standard deviation (SD) or median and interquartile range (IQR) and were compared using the Mann-Whitney test or $t$ test, as appropriate. Qualitative variables were reported as the number and percentage (no., \%) and compared using the $\chi^{2}$ test or Fisher exact test, as appropriate. Means for continuous variables were compared using independent group $t$ tests when the data were normally distributed; otherwise, a nonparametric comparative test was used. The sample size was derived from all eligible patients hospitalized during the study period. All statistical analyses were performed using SPSS Statistics version 23.0 software. The statistical significance level was set at a two-sided $P$ value of $<0.05$.

\section{Results}

During the study period, we collected the medical records of 127 patients with a high-risk common type COVID-19 pneumonia being treated with SDT + MPT (the SDT + MPT group) and 276 patients with a high-risk common type COVID-19 pneumonia treated only with SDT (the SDT group).

\section{Clinical characteristics}

The age, sex, comorbidities and clinical and laboratory test results of patients with high-risk common type COVID19 pneumonia on admission are shown in Tables 1, 2 and

Table 1 Demographic and clinical characteristics of the patients at baseline

\begin{tabular}{|c|c|c|c|c|c|}
\hline & Characteristic & Total $(N=403)$ & $\mathrm{SDT}+\mathrm{MPT}(N=127)$ & $\operatorname{SDT}(N=276)$ & $P$ value \\
\hline & Age (years) & $49.31 \pm 1.05$ & $49.93 \pm 1.183$ & $48.7 \pm 0.9247$ & 0.4087 \\
\hline & Male/female, no (\%) & $\begin{array}{l}224 \\
\quad(55.61 \%) / 179 \\
(44.39 \%)\end{array}$ & $69(54.33 \%) / 58(45.67 \%)$ & $\begin{array}{l}155 \\
(56.16 \%) / 121 \\
(43.84 \%)\end{array}$ & 0.7491 \\
\hline & $\begin{array}{l}\text { Comorbidities: hypertension, coronary heart } \\
\text { disease, diabetes, obesity, chronic lung disease. } \\
\text { no }(\%)\end{array}$ & $231(57.28 \%)$ & $75(59.35 \%)$ & $158(57.19 \%)$ & 0.8601 \\
\hline & Fever & $348(86.4 \%)$ & $115(90.3 \%)$ & $233(84.6 \%)$ & 0.1012 \\
\hline & $\begin{array}{l}\text { Respiratory symptoms: cough, dyspnea, sore } \\
\text { throat }\end{array}$ & $261(64.7 \%)$ & $88(69.2 \%)$ & $173(62.7 \%)$ & 0.3210 \\
\hline & CT: typical coronavirus pneumonia & $403(100 \%)$ & $127(100 \%)$ & $276(100 \%)$ & 0.9999 \\
\hline \multirow[t]{2}{*}{ WBC count } & $4-10 \times 10^{9} / \mathrm{L}$, no $(\%)$ & $221(54.89 \%)$ & $69(54.89 \%)$ & $150(54.3 \%)$ & 0.9151 \\
\hline & $<4 \times 10^{9} / \mathrm{L}$, no $(\%)$ & $182(45.11 \%)$ & $58(45.7 \%)$ & $124(44.8 \%)$ & 0.9151 \\
\hline \multirow{2}{*}{$\begin{array}{l}\text { Lymphocyte } \\
\text { count }\end{array}$} & $0.8-3.2 \times 10^{9} / \mathrm{L}$, no $(\%)$ & $273(67.72 \%)$ & $80(63.0 \%)$ & $177(64.0 \%)$ & 0.8253 \\
\hline & $<0.8 \times 10^{9} / \mathrm{L}$, no $(\%)$ & $145(36.04 \%)$ & $47(37.0 \%)$ & $98(35.6 \%)$ & 0.8253 \\
\hline
\end{tabular}

SDT, Standard treatment; MPT, Methylprednisolone therapy; WBC, White blood cell; CT, Computed tomography 
Table 2 Clinical characteristics and laboratory findings of the patients from Day1 to Day8

\begin{tabular}{|c|c|c|c|c|c|c|c|c|c|}
\hline & & D1 & D2 & D3 & D4 & D5 & D6 & D7 & D8 \\
\hline \multirow{2}{*}{$\begin{array}{l}\text { Lymphocyte } \\
\text { count, } \times 10^{9} / \mathrm{L}\end{array}$} & A & $0.89 \pm 0.51$ & $1.02 \pm 0.52$ & $0.93 \pm 0.54$ & $1.18 \pm 0.63$ & $1.18 \pm 0.79$ & $1.21 \pm 0.59$ & $1.47 \pm 0.71$ & $1.59 \pm 0.89$ \\
\hline & B & $0.79 \pm 0.33$ & $0.91 \pm 0.39$ & $0.79 \pm 0.26$ & $0.97 \pm 0.31$ & $0.99 \pm 0.33$ & $0.92 \pm 0.38$ & $1.06 \pm 0.46$ & $1.17 \pm 0.39$ \\
\hline \multirow[t]{2}{*}{ CRP (mg/L) } & A & $30.33 \pm 6.43$ & $37.73 \pm 8.36$ & $26.28 \pm 5.81$ & $18.13 \pm 3.81$ & $15.32 \pm 5.08$ & $18.17 \pm 3.26$ & $15.63 \pm 3.22$ & $17.00 \pm 4.29$ \\
\hline & B & $19.15 \pm 3.32$ & $13.72 \pm 2.47$ & $21.57 \pm 5.16$ & $16.69 \pm 3.92$ & $17.46 \pm 3.68$ & $13.01 \pm 2.33$ & $19.82 \pm 5.2$ & $13.01 \pm 3.81$ \\
\hline \multirow[t]{2}{*}{ IL-6 (pg/ml) } & A & $13.59 \pm 1.41$ & $11.15 \pm 1.77$ & $16.75 \pm 4.87$ & $10.05 \pm 1.32$ & $11.63 \pm 2.43$ & $11.3 \pm 2.27$ & $6.74 \pm 1.34$ & $8.86 \pm 0.98$ \\
\hline & B & $11.49 \pm 4.43$ & $11.36 \pm 3.18$ & $9.45 \pm 2.47$ & $12.35 \pm 3.88$ & $19.78 \pm 5.48$ & $13.01 \pm 3.51$ & $12.97 \pm 5.21$ & $4.24 \pm 1.12$ \\
\hline \multirow[t]{2}{*}{ Dimer (mg/L) } & A & $1.61 \pm 0.23$ & $2.03 \pm 0.68$ & $1.76 \pm 0.38$ & $2.05 \pm 0.63$ & $1.55 \pm 0.27$ & $1.69 \pm 0.37$ & $2.27 \pm 0.55$ & $1.38 \pm 0.18$ \\
\hline & B & $2.11 \pm 0.65$ & $0.89 \pm 0.12$ & $1.63 \pm 0.19$ & $2.43 \pm 0.73$ & $1.53 \pm 0.23$ & $2.82 \pm 0.46$ & $2.16 \pm 0.29$ & $2.59 \pm 0.59$ \\
\hline \multirow[t]{2}{*}{ LDH (U/L) } & A & $701.8 \pm 41.08$ & $639.8 \pm 109.2$ & $861.2 \pm 125.1$ & $747.4 \pm 97.09$ & $676.6 \pm 85.11$ & $655.8 \pm 93.18$ & $564.3 \pm 41.79$ & $665.1 \pm 75.61$ \\
\hline & B & $668 \pm 47.99$ & $659.3 \pm 53.33$ & $620.4 \pm 43.21$ & $616 \pm 40.98$ & $542.1 \pm 51.51$ & $585.6 \pm 34.58$ & $525.7 \pm 39.1$ & $508.3 \pm 35.74$ \\
\hline \multirow{2}{*}{$\begin{array}{l}\text { Respiratory rate, } \\
\text { breaths/ min }\end{array}$} & A & $24.79 \pm 0.50$ & $24.22 \pm 0.31$ & $25.11 \pm 0.52$ & $23.98 \pm 0.32$ & $23.85 \pm 0.26$ & $23.29 \pm 0.27$ & $23.7 \pm 0.26$ & $23.3 \pm 0.25$ \\
\hline & B & $20.86 \pm 0.56$ & $20.66 \pm 0.79$ & $20.18 \pm 0.71$ & $21.24 \pm 0.67$ & $20.52 \pm 0.67$ & $20.21 \pm 0.54$ & $20.39 \pm 0.63$ & $19.83 \pm 0.61$ \\
\hline \multirow{2}{*}{$\begin{array}{l}\text { Body tempera- } \\
\text { ture, },{ }^{\circ} \mathrm{C}\end{array}$} & A & $37.3 \pm 0.08$ & $37.19 \pm 0.10$ & $36.95 \pm 0.15$ & $36.6 \pm 0.34$ & $36.89 \pm 0.07$ & $36.81 \pm 0.07$ & $36.52 \pm 0.27$ & $36.69 \pm 0.09$ \\
\hline & B & $37.18 \pm 0.08$ & $36.95 \pm 0.09$ & $37.06 \pm 0.09$ & $36.96 \pm 0.07$ & $36.78 \pm 0.07$ & $37 \pm 0.07$ & $37.04 \pm 0.10$ & $37.08 \pm 0.11$ \\
\hline \multirow[t]{2}{*}{$\mathrm{PaO}_{2}(\mathrm{mmHg})$} & A & $73.46 \pm 4.61$ & $84.88 \pm 6.64$ & $76.67 \pm 3.23$ & $82.79 \pm 2.68$ & $74.16 \pm 1.61$ & $78.97 \pm 2.34$ & $81.44 \pm 2.69$ & $81.52 \pm 2.54$ \\
\hline & B & $73.73 \pm 1.90$ & $77.64 \pm 4$ & $85.28 \pm 3.28$ & $77.44 \pm 3.69$ & $89.69 \pm 7.79$ & $89.71 \pm 4.42$ & $88.4 \pm 4.53$ & $83.91 \pm 4.31$ \\
\hline \multirow[t]{2}{*}{$\mathrm{SpO}_{2}(\%)$} & A & $93.17 \pm 1.05$ & $95.67 \pm 1.35$ & $96.68 \pm 0.34$ & $97.63 \pm 0.25$ & $97.43 \pm 0.27$ & $98.29 \pm 0.30$ & $98.12 \pm 0.30$ & $97.76 \pm 0.37$ \\
\hline & B & $96.39 \pm 0.62$ & $97.74 \pm 0.21$ & $97.8 \pm 0.26$ & $97.63 \pm 0.27$ & $97.75 \pm 0.25$ & $98.21 \pm 0.28$ & $97.85 \pm 0.32$ & $98.36 \pm 0.28$ \\
\hline
\end{tabular}

${ }^{\circ} \mathrm{C}$, Centigrade; min, Minute; $\mathrm{mm} \mathrm{Hg}$, Millimeter of mercury; CRP, C-reactive protein; mg/L Milligrams per liter; pg/ml, Pictogram per milliliter; ng/ml, Nanogram per milliliter; $\mathrm{LDH}$, Lactic acid dehydrogenase; U/L, Unit per liter; $\mathrm{PaO}_{2}$, pressure of arterial oxygen;IL-6, interleukin 6; $\mathrm{SpO}_{2}$, pulse oximeter oxygen saturation. A, SDT + MPT. B, SDT

Table 3 Clinical characteristics and laboratory findings of the patients from Day9 to 16

\begin{tabular}{|c|c|c|c|c|c|c|c|c|c|}
\hline & & D9 & D10 & D11 & D12 & D13 & D14 & D15 & D16 \\
\hline \multirow{2}{*}{$\begin{array}{l}\text { Lymphocyte } \\
\text { count, } \times 10^{9} / \mathrm{L}\end{array}$} & $\mathrm{A}$ & $1.58 \pm 0.87$ & $1.67 \pm 0.89$ & $1.48 \pm 0.79$ & $1.72 \pm 0.94$ & $1.49 \pm 0.80$ & $1.47 \pm 0.67$ & $1.61 \pm 0.66$ & $1.41 \pm 0.56$ \\
\hline & $\mathrm{B}$ & $0.99 \pm 0.32$ & $1.24 \pm 0.52$ & $1.01 \pm 0.31$ & $1.27 \pm 0.37$ & $1.05 \pm 0.35$ & $1.18 \pm 0.45$ & $1.25 \pm 0.55$ & $1.08 \pm 0.52$ \\
\hline \multirow[t]{2}{*}{ CRP (mg/L) } & A & $14.13 \pm 3.68$ & $6.41 \pm 1.36$ & $12.63 \pm 4.05$ & $10.56 \pm 5.74$ & $9.26 \pm 3.57$ & $4.27 \pm 1.32$ & $5.12 \pm 1.39$ & $4.75 \pm 1.15$ \\
\hline & $\mathrm{B}$ & $14.67 \pm 4.41$ & $9.42 \pm 3.22$ & $8.26 \pm 3.08$ & $5.96 \pm 1.89$ & $18 \pm 1.62$ & $5.99 \pm 2.07$ & $34 \pm 2.17$ & $=1.44$ \\
\hline \multirow[t]{2}{*}{ IL-6 (pg/ml) } & $\mathrm{A}$ & $9.99 \pm 1.19$ & $7.60 \pm 1.41$ & $6.77 \pm 1.12$ & $6.98 \pm 0.95$ & $6.55 \pm 0.55$ & $6.41 \pm 1.03$ & $4.46 \pm 0.56$ & $5.55 \pm 0.65$ \\
\hline & $\mathrm{B}$ & $5.5 \pm 1.25$ & $6.63 \pm 0.71$ & $6.16 \pm 0.83$ & $5.25 \pm 0.83$ & $5.15 \pm 0.88$ & $6.39 \pm 0.88$ & $5.51 \pm 0.72$ & $5.15 \pm 0.67$ \\
\hline \multirow[t]{2}{*}{ D-Dimer $(\mathrm{mg} / \mathrm{L})$} & A & $1.71 \pm 0.37$ & $1.44 \pm 0.21$ & $1.06 \pm 0.09$ & $1.24 \pm 0.14$ & $1.51 \pm 0.24$ & $1.65 \pm 0.29$ & $1.59 \pm 0.30$ & $0.77 \pm 0.11$ \\
\hline & $\mathrm{B}$ & $2.75 \pm 0.68$ & $2.81 \pm 0.56$ & $2.61 \pm 0.93$ & $2.59 \pm 0.84$ & $2.29 \pm 0.83$ & $1.93 \pm 0.50$ & $1.92 \pm 0.33$ & $1.13 \pm 0.18$ \\
\hline \multirow[t]{2}{*}{ LDH (U/L) } & $\mathrm{A}$ & $545.6 \pm 81$ & $563.4 \pm 50.36$ & $562.6 \pm 73.89$ & $511.7 \pm 47.01$ & $470.9 \pm 62.18$ & $488.1 \pm 72.08$ & $492 \pm 45.23$ & $401.9 \pm 35.52$ \\
\hline & $\mathrm{B}$ & $545.8 \pm 35.2$ & $526 \pm 30.71$ & $475.7 \pm 41.26$ & $405.1 \pm 33.84$ & $490.3 \pm 44.95$ & $461.6 \pm 26.56$ & $471.1 \pm 32.1$ & $448.4 \pm 44.9$ \\
\hline \multirow{2}{*}{$\begin{array}{l}\text { Respiratory rate, } \\
\text { breaths min }\end{array}$} & A & $23.04 \pm 0.28$ & $22.78 \pm 0.20$ & $23.47 \pm 0.25$ & $23.43 \pm 0.26$ & $23.34 \pm 0.26$ & $23.46 \pm 0.30$ & $23.29 \pm 0.22$ & $23.23 \pm 0.21$ \\
\hline & $\mathrm{B}$ & $19.64 \pm 0.62$ & $19.96 \pm 0.58$ & $19.96 \pm 0.46$ & $20.08 \pm 0.53$ & $19.31 \pm 0.49$ & $19.58 \pm 0.52$ & $19.41 \pm 0.48$ & $18.59 \pm 0.45$ \\
\hline \multirow{2}{*}{$\begin{array}{l}\text { Body tempera- } \\
\text { ture },{ }^{\circ} \mathrm{C}\end{array}$} & A & $36.73 \pm 0.05$ & $36.69 \pm 0.06$ & $36.69 \pm 0.06$ & $36.62 \pm 0.04$ & $36.69 \pm 0.06$ & $36.64 \pm 0.05$ & $36.68 \pm 0.05$ & $36.54 \pm 0.13$ \\
\hline & B & $36.9 \pm 0.08$ & $37.1 \pm 0.11$ & $36.07 \pm 1.00$ & $38.08 \pm 0.94$ & $37.13 \pm 0.10$ & $37.12 \pm 0.08$ & $37.01 \pm 0.08$ & $36.92 \pm 0.08$ \\
\hline \multirow[t]{2}{*}{$\mathrm{PaO}_{2}(\mathrm{mmHg})$} & A & $81.82 \pm 2.85$ & $76.26 \pm 2.41$ & $79.07 \pm 2.69$ & $84.36 \pm 3.07$ & $86.77 \pm 5.61$ & $83.11 \pm 4.59$ & $81.12 \pm 3.80$ & $93.33 \pm 5.08$ \\
\hline & B & $84.09 \pm 5.55$ & $78.5 \pm 2.81$ & $81.49 \pm 1.57$ & $84.57 \pm 4.16$ & $85.25 \pm 5.34$ & $87.33 \pm 3.76$ & $85.5 \pm 9.5$ & $92.77 \pm 3.17$ \\
\hline \multirow[t]{2}{*}{$\mathrm{SpO}_{2}(\%)$} & A & $97 . .92 \pm 0.28$ & $98.25 \pm 0.31$ & $98.13 \pm 0.28$ & $98.14 \pm 0.31$ & $98.31 \pm 0.37$ & $98.31 \pm 0.40$ & $98.5 \pm 0.39$ & $98.5 \pm 0.28$ \\
\hline & B & $98.1 \pm 0.29$ & $98.34 \pm 0.22$ & $98.16 \pm 0.33$ & $98.28 \pm 0.34$ & $98.85 \pm 0.28$ & $98.6 \pm 0.26$ & $99.13 \pm 0.24$ & $98.87 \pm 0.34$ \\
\hline
\end{tabular}

${ }^{\circ} \mathrm{C}$, Centigrade; min, Minute; WBC, White blood cell; mm Hg, Millimeter of mercury; CRP, C-reactive protein; mg/L Milligrams per liter; pg/ $\mathrm{ml}$, Pictogram per milliliter; ng/ml, Nanogram per milliliter; $\mathrm{LDH}$, Lactic acid dehydrogenase; U/L, Unit per liter; $\mathrm{PaO}_{2}$, pressure of arterial oxygen; IL-6, interleukin 6; $\mathrm{SpO}_{2}$, pulse oximeter oxygen saturation. A, SDT+MPT. B, SDT

3. Table 1 shows that the clinical characteristics of the SDT + MPT and SDT groups were similar and comparable. Tables 2 and 3 show the average lymphocyte count, CRP,
IL-6 level, LDH, respiratory rate, $\mathrm{SpO} 2, \mathrm{PaO} 2$, D-dimer and body temperature on days $1-16$. Figures 3,4 and 5 show the changing trends in lymphocyte count, CRP, IL-6 level, LDH, 
Fig. 3 Variation characteristics of body temperature, respiratory rate, pressure of arterial oxygen and oxygen saturation in patients with a high-risk common type COVID-19 pneumonia in the two groups
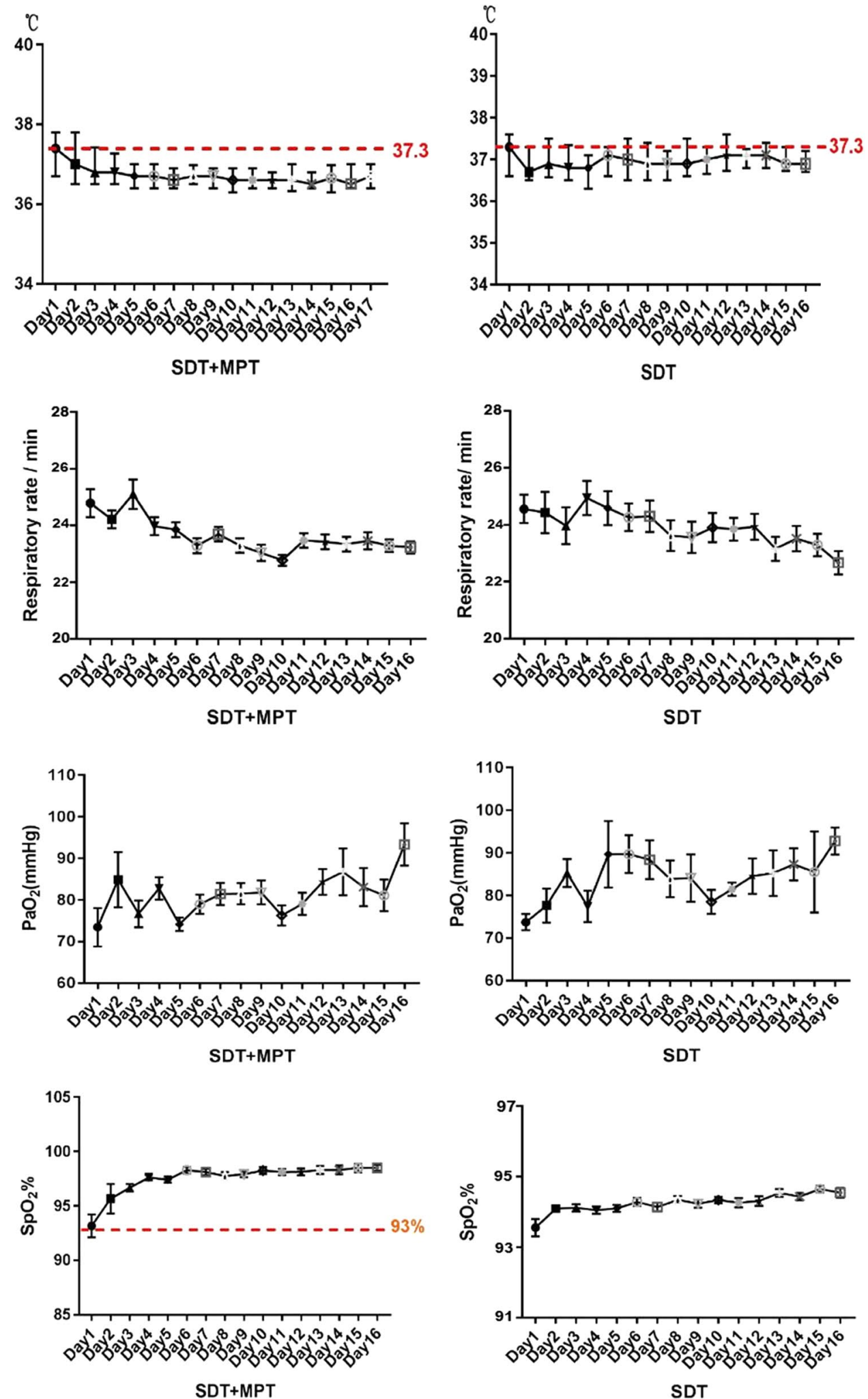

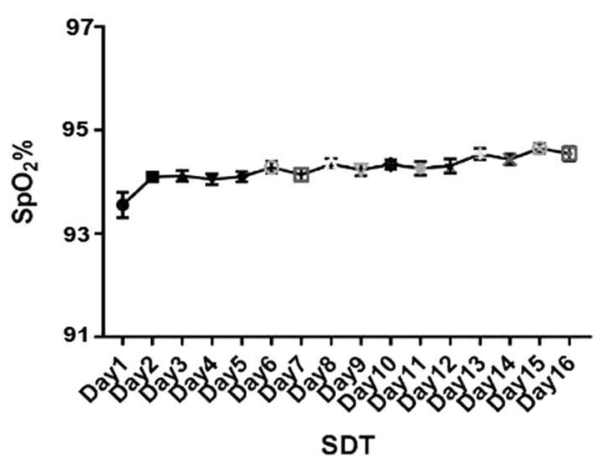

respiratory rate, $\mathrm{SpO} 2, \mathrm{PaO} 2, \mathrm{D}$-dimer and body temperature on days 1-16.

Tables 2 and 3 and Figs. 3, 4 and 5 show that the changing trends of lymphocyte count, CRP, IL-6 level, LDH, respiratory rate, $\mathrm{SpO} 2, \mathrm{PaO} 2$, D-dimer and body temperature are similar between the SDT + MPT and SDT groups. The SDT + MPT group seemed to improve faster than the SDT group. However, the results were not statistically significant. 
Fig. 4 Variation characteristics of lymphocyte count and $\mathrm{C}$-reactive protein in patients with a high-risk common type COVID-19 pneumonia in the two groups
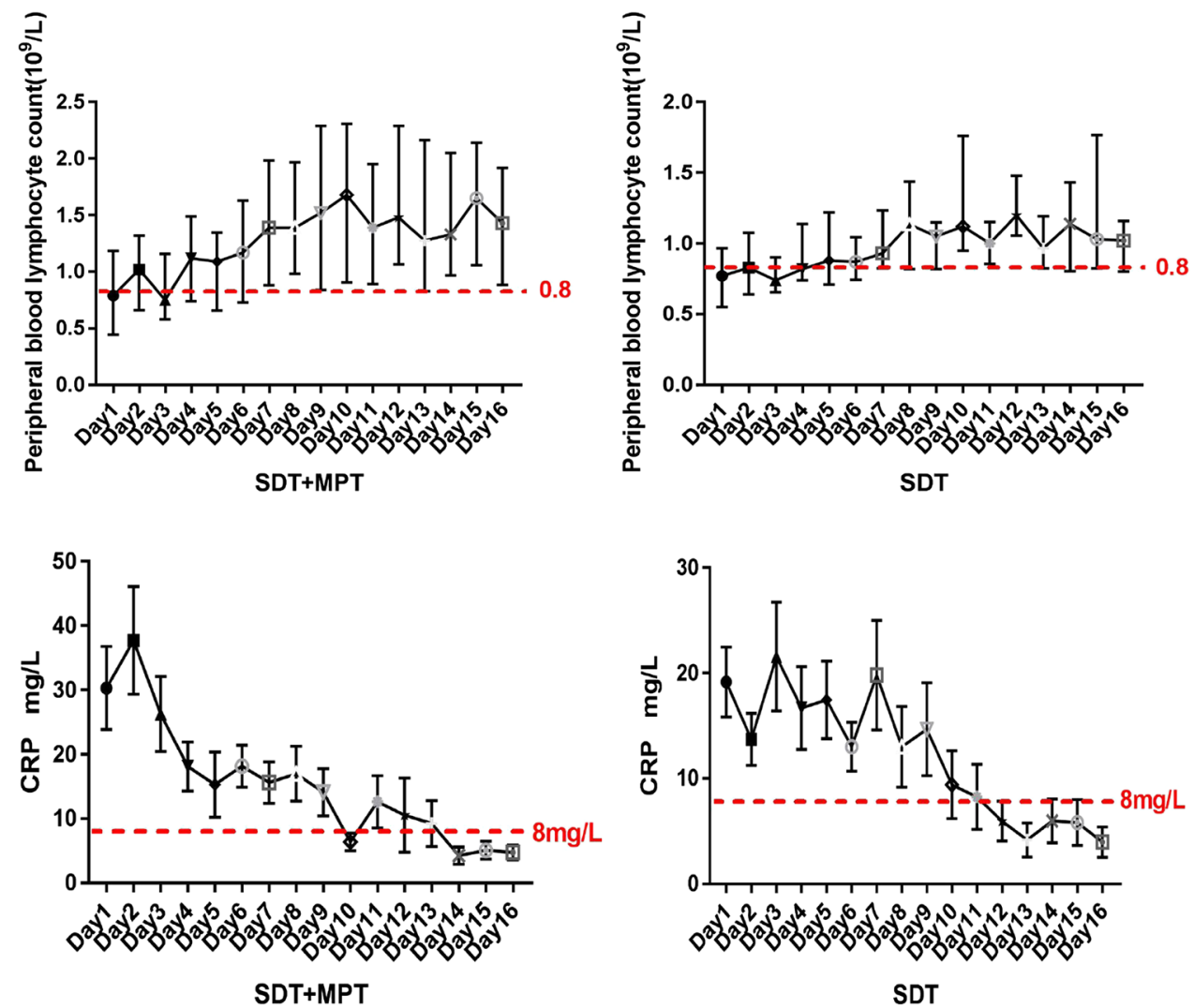

Patients in the SDT + MPT group treated with methylprednisolone received an intravenous injection at a median interval of five days (IQR, 3 to 7 days). No deaths or methylprednisolone side effects occurred in either the SDT + MPT or the SDT group. None of the patients received mechanical ventilation or extracorporeal membrane oxygenation.

\section{Average hospitalization days}

The average hospitalization was $14.56 \pm 0.57$ days for the SDT + MPT group and $16.55 \pm 0.3$ days for the SDT group. There was significant difference between the two groups $(t=3.346, p=0.0009)$. Figure 6A compares the average number of days for hospitalization days in patients with a high-risk common type of COVID-19 pneumonia in the two groups.

\section{The 16-day nucleic acid negative rate}

The 16-day nucleic acid negative rate was $81.73 \%$ (104/127) for the SDT + MPT group and 65.27\% (180/276) for the SDT group. These findings represented a statistically significant difference between the two groups $(p=0.0006)$. Figure 6B shows the differences in the 16-day nucleic acid negative rates for patients with a high-risk common type COVID-19 pneumonia in the SDT + MPT and SDT groups.

\section{Rate of progression to severe type COVID-19}

The rate of progression to severe type COVID-19 pneumonia was $21.26 \%(27 / 127)$ for the SDT + MPT group and $32.4 \%$ (89/276) for the SDT group. These data represented a statistically significant difference between the two groups $(p=0.0247)$. Figure $6 \mathrm{C}$ shows the differences between the SDT + MPT and SDT groups in the rates of progression for patients with a high-risk common type COVID-19 pneumonia to a more severe type.

\section{Discussion}

For patients with a high-risk common type COVID-19 pneumonia, the changing trends in lymphocyte count, CRP, IL-6 level, LDH, respiratory rate, $\mathrm{SpO} 2, \mathrm{PaO}$, $\mathrm{D}$-dimer and body temperature did not significantly differ between the SDT + MPT and SDT groups. Our results were consistent with a report by Wang et al. [23]. A pattern of cytokines resembling secondary hemophagocytic lymphohistiocytosis was associated with SARS-CoV-2 infection [24]. One study showed that patients with higher IL-6 
Fig. 5 Variation characteristics of interleukin 6, lactic acid dehydrogenase and D-dimer in patients with a high-risk common type COVID-19 pneumonia in the two groups
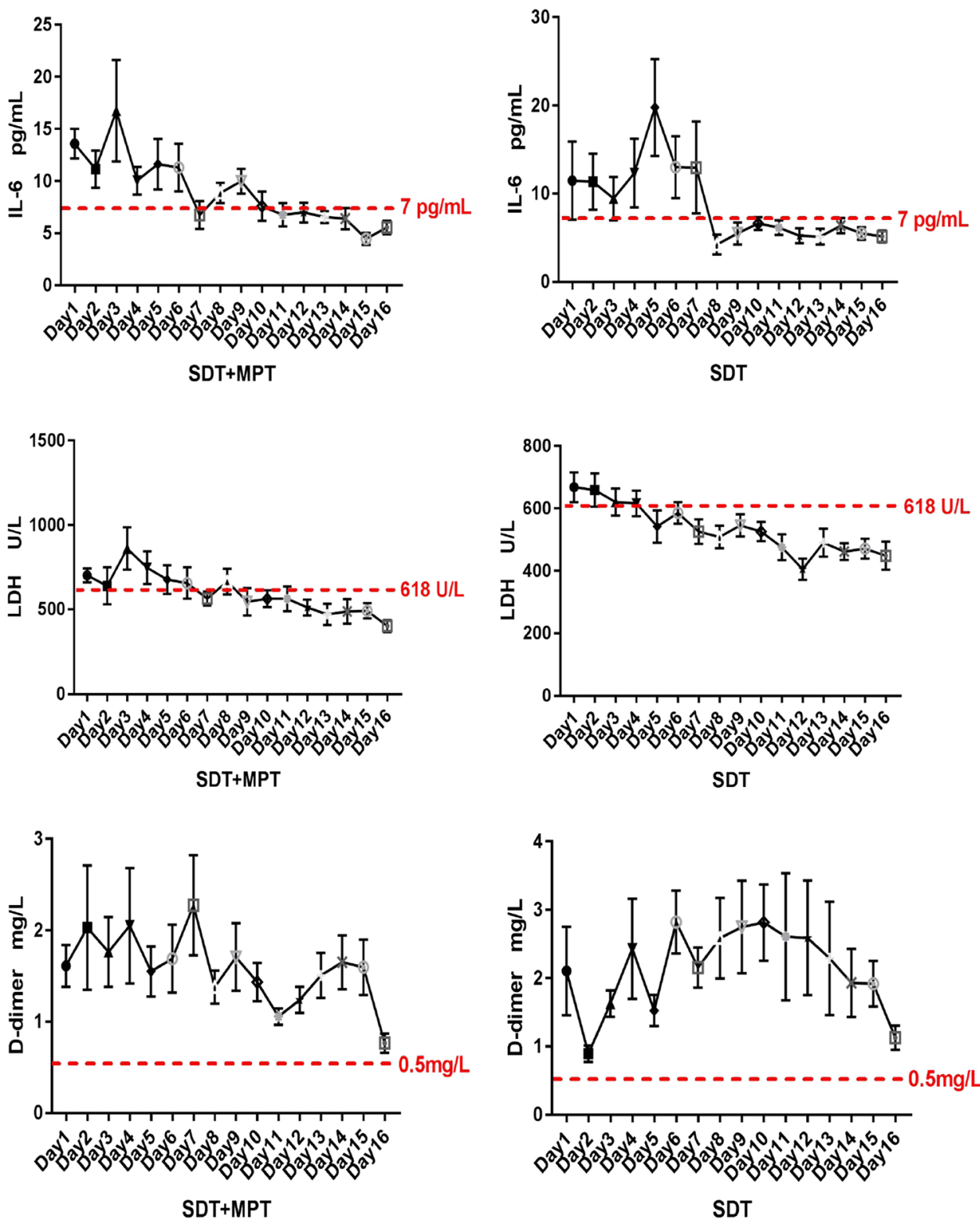

levels responded better to methylprednisolone treatment as proposed in this study because IL-6 is considered a surrogate marker for the extent of lung involvement. Because these results show that patients with more extensive lung damage might benefit more from methylprednisolone treatment, our findings are consistent with these studies [25].

Another study suggested possible benefits in the use of corticosteroids in patients with severe COVID-19 and hyperinflammation diagnosed based on their cytokine elevation profile [26]. In our research, methylprednisolone treatment quickly improved the respiratory rate, $\mathrm{SpO} 2$ and $\mathrm{PaO} 2$. Furthermore, the protective effect of methylprednisolone was more profound in cases showing higher IL-6, D-dimer and CRP levels; the exception was LDH.
This finding is not consistent with the literature [25], likely because our research subjects were not in the severe stage of COVID-19 pneumonia.

In this study, patients received intravenous injections of methylprednisolone for a median of 5 days. Siddiqi et al. reported a median of 10 days; this difference may be related to the severity of the disease and the distinct stage during treatment. The latter cases were primarily the severe type of COVID-19 pneumonia [27]. This suggests that the length of time for methylprednisolone treatment was significantly shorter in patients with a high-risk common type COVID19 pneumonia than in those with a severe type COVID-19 pneumonia. Simultaneously, the side effects were lower in 

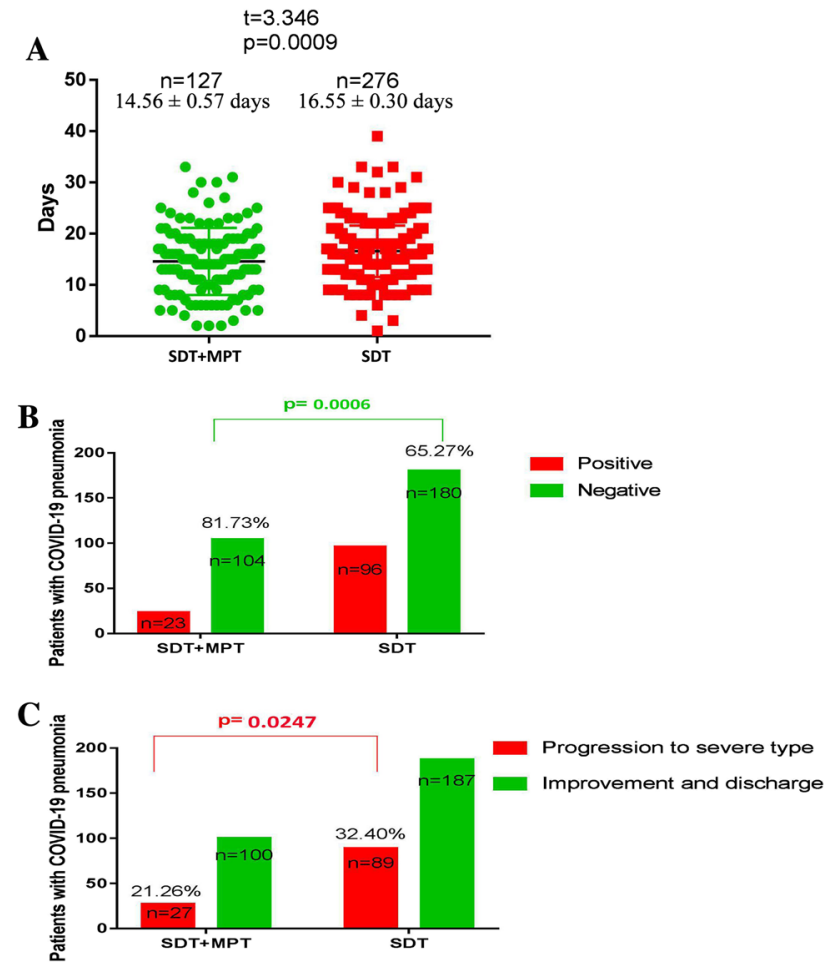

Fig. 6 Contradistinction of the average hospitalization days, 16-day nucleic acid negative rate and the rate of progression to a severe stage in patients with a high-risk common type COVID-19 pneumonia in the two groups. A contrast of hospitalization days; $\mathbf{B}$ contrast of 16-day nucleic acid negative rate; $\mathbf{C}$ contrast of progression to severe type

the high-risk common type COVID-19 pneumonia than in the severe type.

In contrast, our results showed that the average number of hospitalized days for patients with a high-risk common type COVID-19 pneumonia was significantly shorter in patients treated with methylprednisolone than in those not treated. Furthermore, the progression rate in patients with a highrisk common type COVID-19 pneumonia to a more severe type was visibly lower in patients treated with methylprednisolone than in those not treated.

Finally, the 16-day nucleic acid negative rate of patients with a high-risk common type COVID-19 pneumonia was markedly higher in patients treated with methylprednisolone than in those not treated. These results support the use of methylprednisolone in patients with a high-risk common type COVID-19 pneumonia. Siddiqi et al. also reported that early treatment with anti-inflammatory therapies such as steroids when hypoxia develops may be beneficial due to the predominant role of inflammation in the disease's pathophysiology [27].

Some studies have reported that methylprednisolone use in patients with SARS-CoV-2 may be harmful because of a delay in viral clearance; however, this theory was not confirmed in a study by Fang et al. [28]. Shang et al. [29] concluded that the evidence regarding the use of methylprednisolone was inconclusive. It is worth considering whether methylprednisolone should be used in the course of COVID19 pneumonia and when the optimal timing for MPT treatment is.

However, in our study, the 16-day nucleic acid negative rate of patients with a high-risk common type COVID-19 pneumonia was markedly higher in patients treated with methylprednisolone than in those not treated. This finding means that methylprednisolone treatment in patients with a high-risk common type COVID-19 pneumonia may be more beneficial for the 16th-day clearance of SARS-CoV-2 infection than without its treatment. The difference is attributable to the anti-inflammatory effects of methylprednisolone in patients with COVID-19 pneumonia, and the early relief of dyspnea is more conducive to ensure oxygen supply to all organs and improve systemic immunity.

Although some guidelines recommend using methylprednisolone only in COVID-19 patients who are intubated [30, 31 ], our research indicated that methylprednisolone treatment was beneficial in patients with a high-risk common type COVID-19. These benefits apply to the 16-day nucleic acid negative rate, the rate of progression to severe COVID19 pneumonia and the average hospitalization days. This also means that the use of methylprednisolone may be appropriate in patients with a high-risk common type COVID-19 pneumonia.

If methylprednisolone is used to only treat more advanced stages of COVID-19, we might miss a therapeutic window to prevent the progression to severe acute respiratory distress syndrome; therefore, this may prevent the need for mechanical ventilation, death and high costs. However, the optimal period for methylprednisolone treatment remains to be clarified. In our study, methylprednisolone use in patients with a high-risk common type COVID-19 pneumonia was effective and beneficial, meaning that patients with a highrisk common type COVID-19 pneumonia present an optimal opportunity for timely treatment with methylprednisolone.

Nevertheless, our study has a few limitations. First of all, because the medical records were not detailed, our retrospective study did not allow us to collect all clinical data related to the patients; as a result, the duration of symptoms that may be a high risk of progression to severe/critical COVID19 were not evaluated. Second, the observation duration of patients in this study may not be adequate to affirm how long the treatment efficacy of methylprednisolone; will last or if death or other side effects occur after patient discharge? This problem is also the focus of our future study. One thing was clear, no patient death occurred within 3 months after discharge though our follow-up.

Our study suggests that methylprednisolone has potential efficacy in the treatment of patients with a high-risk 
common type COVID-19 pneumonia, but it is necessary to implement randomized clinical trials to clarify the role of methylprednisolone in treatment. The optimal timing for the use of methylprednisolone and the risk/benefit ratio of treatment remain to be documented. Furthermore, it is unknown if the same methylprednisolone dose would be appropriate for different stages of COVID-19 and what the therapeutic ceiling might be.

\section{Conclusions}

The data from the medical records of 403 patients with a high-risk common type COVID-19 pneumonia were collected. Of the total, 127 patients were in the SDT + MPT group, and 276 patients were in the SDT group. No deaths or drug side effects occurred in either group. None of the patients received mechanical ventilation or extracorporeal membrane oxygenation. Patients in the SDT + MPT group received an intravenous injection of methylprednisolone at a median interval of 5 days (IQR, 3 to 7 days). The changing trends in lymphocyte count, CRP, IL-6 level, LDH, respiratory rate, $\mathrm{SpO} 2, \mathrm{PaO} 2, \mathrm{D}$-dimer and body temperature were similar between the two groups. The SDT + MPT group seemed to improve faster than the SDT group; however, the difference was not statistically significant.

The average number of days hospitalized and the rate of progression to the severe type of COVID-19 pneumonia were significantly lower in the SDT + MPT group than in the SDT group. The 16-day nucleic acid negative rate was markedly higher in the SDT + MPT group than in the SDT group. These results support the use of methylprednisolone in patients with a high-risk common type COVID-19 pneumonia. Methylprednisolone therapy prevents patients with a high-risk common type COVID-19 pneumonia from progressing to the severe stage. This study is the first to demonstrate that patients with a high-risk common type COVID-19 pneumonia may benefit from the timely use of methylprednisolone, and an earlier stage of COVID-19 pneumonia may be an optimal opportunity for the timely treatment with methylprednisolone.

Acknowledgements We would like to acknowledge the fast work of the institutional ethics board of the Qun'li branch of the First Affiliated Hospital of Harbin Medical University and Kang'an Hospital of Mudanjiang. We thank all patients in the study.

Author contributions Q. X. Zeng, Y. H. Zhang, Y. W. Gong, W. Zhang and Z. Z. He collected the epidemiological and clinical data. B. Liu, J. J. Li, Y. W. Yang and H. Qu summarized all data. L. Liu drafted the manuscript. L. Liu and L. C. Che revised the final manuscript.

Funding The Rapid Service Fee, and the Open Access fee of this study was supported by following funds: 1 . The National Key Laboratory of Sponsored by Open Project of State Key Laboratory of Respiratory Disease (Project Funding Number: SKLRD-OP-201902)". 2. The National Key Laboratory of Urban Water Resources and Water Environment Full Funds. (Project Funding Number: ESK201602.). 3. Project supported by Bethune Medical Science Research Foundation (Item Number: SG059EN).

Data availability After publication, the data will be made available to others on reasonable requests to the corresponding author. Availability of data and material also need to be approved by the institutional ethics board of the Qun'li branch of the First Affiliated Hospital of Harbin Medical University and Kang'an Hospital of Mudanjiang.

\section{Declarations}

Conflict of interest We have not any conflict of interests to declare. LiChun-Che is a professor of Harbin Medical University.

Ethical approval Ethical approval by the institutional ethics board of the Qun'li branch of the First Affiliated Hospital of Harbin Medical University and Kang'an Hospital of Mudanjiang was obtained for the analysis and summary of clinical data from COVID-19-infected inpatients (The ethical approval number is 2020-098).

Informed consent Informed written consent was waived by the Ethics Commission of the Qun'li branch of the First Affiliated Hospital of Harbin Medical University and Kang'an Hospital of Mudanjiang in consideration of the retrospective nature of the study and the urgency of reporting on emerging infectious diseases. All relevant ethical safeguards have been met in line with the Declaration of Helsinki.

Consent for publication All authors have been personally and actively involved in substantive work leading to the report, and will hold themselves jointly and individually responsible for its content.

Authorship All named authors meet the International Committee of Medical Journal Editors (ICMJE) criteria for authorship for this article, take responsibility for the integrity of the work as a whole, and have given their approval for this version to be published.

\section{References}

1. World Health Organization. Novel coronavirus (2019-nCoV): situation report-15. https://www.who.int/docs/default-source/coron aviruse/situation-reports/20200204-sitrep-15-ncov.pdf. Accessed 5 Feb 2020.

2. Hui David S, Azhar Esam I, Madani Tariq A, et al. The continuing 2019-nCoV epidemic threat of novel coronaviruses to global health - the latest 2019 novel coronavirus outbreak in Wuhan, China. Int J Infect Dis. 2019;2020(91):264-6.

3. Zhang W, Zhao Y, Zhang F, et al. The use of anti-inflammatory drugs in the treatment of people with severe coronavirus disease 2019 (COVID-19): The experience of clinical immunologists from China. Clin Immunol. 2020;25:108393.

4. Russell CD, Millar JE, Baillie JK. Clinical evidence does not support corticosteroid treatment for 2019-nCoV lung injury. Lancet. 2020;395(10223):473-5.

5. Guan WJ, Ni ZY, Hu Y, et al. Clinical characteristics of coronavirus disease 2019 in China. N Engl J Med. 2020;382(18):1708-20.

6. McCreary EK, Pouge JM. COVID-19 treatment: a review of early and emerging options. Open Forum Infect Dis. 2020;7(4):ofaa105. 
7. Wang D, Hu B, Hu C, et al. Clinical characteristics of 138 hospitalized patients with 2019 novel coronavirus-infected pneumonia in Wuhan, China. JAMA. 2020;323(11):1061-9.

8. Yang X, Yu Y, Xu J, et al. Clinical course and outcomes of critically ill patients with SARS-CoV-2 pneumonia in Wuhan, China: a single-centered, retrospective, observational study. Lancet Respir Med. 2020;8(5):475-81.

9. Edalatifard M, Akhtari M, Salehi M, et al. Intravenous methylprednisolone pulse as a treatment for hospitalised severe COVID19 patients: results from a randomised controlled clinical trial. Eur Respir J. 2020;56(6):2002808. https://doi.org/10.1183/13993003. 02808-2020.

10. Fernández-Cruz A, Ruiz-Antorán B, Muñoz-Gómez A, et al. A retrospective controlled cohort study of the impact of glucocorticoid treatment in SARS-CoV-2 infection mortality. Antimicrob Agents Chemother. 2020;64(9):e01168-e1220. https://doi.org/10. 1128/AAC.01168-20.

11. Wang Y, Jiang W, He Q, et al. A retrospective cohort study of methylprednisolone therapy in severe patients with COVID-19 pneumonia. Signal Transduct Target Ther. 2020;5(1):57. https:// doi.org/10.1038/s41392-020-0158-2.

12. Fadel R, Morrison AR, Vahia A, et al. Early short-course corticosteroids in hospitalized patients with COVID-19. Clin Infect Dis. 2020;71(16):2114-20.

13. Bartoletti M, Marconi L, Scudeller L, et al. Efficacy of corticosteroid treatment for hospitalized patients with severe COVID-19: a multicentre study. Clin Microbiol Infect. 2021;27(1):105-11. https://doi.org/10.1016/j.cmi.2020.09.014.

14. Kosaka M, Yamazaki Y, Maruno T, et al. Corticosteroids as adjunctive therapy in the treatment of coronavirus disease 2019: a report of two cases and literature review. J Infect Chemother. 2021;27(1):94-8. https://doi.org/10.1016/j.jiac.2020.09.007.

15. Wu C, Hou D, Du C, et al. Corticosteroid therapy for coronavirus disease 2019-related acute respiratory distress syndrome: a cohort study with propensity score analysis. Crit Care. 2020;24(1):643. https://doi.org/10.1186/s13054-020-03340-4.

16. RECOVERY Collaborative Group, Horby P, Lim WS, et al. Dexamethasone in hospitalized patients with Covid-19. N Engl J Med. 2021;384(8):693-704. https://doi.org/10.1056/NEJMoa2021436.

17. Tomazini BM, Maia IS, Cavalcanti AB, et al. Effect of dexamethasone on days alive and ventilator-free in patients with moderate or severe acute respiratory distress syndrome and COVID-19: the CoDEX Randomized Clinical Trial. JAMA. 2020;324(13):130716. https://doi.org/10.1001/jama.2020.17021.

18. Guan WJ, Ni ZY, Hu Y, et al. Clinical characteristics of coronavirus disease 2019 in China. N Engl J Med. 2020. https://doi.org/ 10.1056/NEJMoa2002032.

19. World Health Organization. Clinical management of severe acute respiratory infection when novel coronavirus $(\mathrm{nCoV})$ infectionis suspected: interimguidance; 2020. https://www.who.int/publi cations-detail/clinical-managementof-severe-acute-respiratoryinfection-when-novelcoronavirus-(ncov)-infection-is-suspected. Accessed 31 Jan 2020.

20. Zhou YH, Qin YY, Lu YQ, Sun F, Yang S, Harypursat V, Tang SQ, Huang YQ, He XQ, Zeng YM, Li Y, Xu XL, Zhao T, Chen YK. Effectiveness of glucocorticoid therapy in patients with severe novel coronavirus pneumonia: protocol of a randomized controlled trial. Chin Med J (Engl). 2020;133:1080.

21. Zhou W, Liu Y, Tian D, Wang C, Wang S, Cheng J, Hu M, Fang $\mathrm{M}, \mathrm{Gao}$ Y. Potential benefits of precise corticosteroids therapy for severe 2019-nCoV pneumonia. Signal Transduct Target Ther. 2020;5:18. https://doi.org/10.1038/s41392-020-0127-9.

22. World Medical Association. 2013. WMA Declaration of Helsinkiethical principles for medical research involving human subjects. World Medical Association, Ferney-Voltaire, France.

23. Wang Y, Jiang W, He Q, Wang C, Wang B, Zhou P, Dong N, Tong $\mathrm{Q}$. A retrospective cohort study of methylprednisolone therapy in severe patients with COVID-19 pneumonia. Signal Transduct Target Ther. 2020;5:57. https://doi.org/10.1038/s41392-020-0158-2.

24. Huang C, Wang Y, Li X, Ren L, Zhao J, Hu Y, Zhang L, Fan G, Xu J, Gu X, Cheng Z, Yu T, Xia J, Wei Y, Wu W, Xie X, Yin W, Li H, Liu M, Xiao Y, Gao H, Guo L, Xie J, Wang G, Jiang R, Gao Z, Jin Q, Wang J, Cao B. Clinical features of patients infected with 2019 novel coronavirus in Wuhan, China. Lancet. 2020;395:497506. https://doi.org/10.1016/S0140-6736(20)30183-5.

25. Wu C, Chen X, Cai Y, Xia J, Zhou X, Xu S, Huang H, Zhang L, Zhou X, Du C, Zhang Y, Song J, Wang S, Chao Y, Yang Z, Xu J, Zhou X, Chen D, Xiong W, Xu L, Zhou F, Jiang J, Bai C, Zheng J, Song Y. Risk factors associated with acute respiratory distress syndrome and death in patients with coronavirus disease 2019 pneumonia in Wuhan, China. JAMA Intern Med. 2020. https:// doi.org/10.1001/jamainternmed.2020.0994.

26. Mehta P, McAuley DF, Brown M, Sanchez E, Tattersall RS, Manson JJ, HLH Across Speciality Collaboration UK. COVID-19: consider cytokine storm syndromes and immunosuppression. Lancet 2020;395:1033-1034. https://doi.org/10.1016/S0140-6736(20) 30628-0.

27. Siddiqi HK, Mehra MR. COVID-19 Illness in native and immunosuppressed states: a clinical-therapeutic staging proposal. J Heart Lung Transpl. 2020. https://doi.org/10.1016/j.healun.2020.03.012.

28. Fang X, Mei Q, Yang T, Li L, Wang Y, Tong F, Geng S, Pan A. Low-dose corticosteroid therapy does not delay viral clearance in patients with COVID-19. J Infect. 2020. https://doi.org/10.1016/j. jinf.2020.03.039.

29. Shang L, Zhao J, Hu Y, Du R, Cao B. On the use of corticosteroids for 2019-nCoV pneumonia. Lancet. 2020;395:683-4. https://doi. org/10.1016/S0140-6736(20)30361-5.

30. Alhazzani W, Moller MH, Arabi YM, Loeb M, Gong MN, Fan E, Oczkowski S, Levy MM, Derde L, Dzierba A, Du B, Aboodi M, Wunsch H, Cecconi M, Koh Y, Chertow DS, Maitland K, Alshamsi F, Belley-Cote E, Greco M, Laundy M, Morgan JS, Kesecioglu J, McGeer A, Mermel L, Mammen MJ, Alexander PE, Arrington A, Centofanti JE, Citerio G, Baw B, Memish ZA, Hammond N, Hayden FG, Evans L, Rhodes A. Surviving Sepsis Campaign: guidelines on the management of critically ill adults with coronavirus disease 2019 (COVID-19). Crit Care Med. 2020. https://doi.org/10.1097/CCM.0000000000004363.

31. Bhimraj A, Morgan RL, Shumaker AH, Lavergne V, Baden L, Cheng VC, Edwards KM, Gandhi R, Muller WJ, O'Horo JC, Shoham S, Murad MH, Mustafa RA, Sultan S, Falck-Ytter Y. Infectious Diseases Society of America guidelines on the treatment and management of patients with COVID-19. Clin Infect Dis. 2020. https://doi.org/10.1093/cid/ciaa478.

Publisher's Note Springer Nature remains neutral with regard to jurisdictional claims in published maps and institutional affiliations. 